\title{
Clinical pharmacology of cefuroxime and cefuroxime axetil in infants and children
}

\author{
Gian Maria Pacifici* \\ Associate Professor of Pharmacology, via Sant'Andrea 32, 56127 Pisa, Italy
}

\begin{abstract}
Cefuroxime is a second-generation cephalosporin $\beta$-lactamase resistant active against gram-negative and gram-positive organisms and the prodrug cefuroxime axetil is the drug of choice for treatment of Lyme disease. Cefuroxime inhibits bacterial cell wall synthesis, is bactericidal, and is one of the few cephalosporins available for oral, intravenous, and intramuscular administration. Cefuroxime is rapidly absorbed when given by mouth, and its blood concentrations remarkably vary among subjects, but the drug has not adverse-effects even when is given at high doses. The gastrointestinal absorption-rate of cefuroxime axetil is $70 \%$, and after hydrolysis it relays cefuroxime. Parenteral dosing-regimens consist of $25 \mathrm{mg} / \mathrm{kg}$ in infants and dosing intervals decrease with increasing postnatal age. Cefuroxime oral dosingregimens are: $10,20 \mathrm{mg} / \mathrm{kg}$ and $250 \mathrm{mg}$ twice-daily in children aged up to one year, 2 to 11 and 12 to 17 years, respectively. Elimination half-live are: 6 hours in the first week of life and 1.8 hours in children aged up to 6 years. Cefuroxime is efficacy and safe for prophylaxis and treatment of respiratory-tract and acute urinary-tract infections, pneumoniae, acute otitis media, and sinusitis in children. Prophylaxis for surgical procedures requires $50 \mathrm{mg} / \mathrm{kg}$ before procedure and then $30 \mathrm{mg} / \mathrm{kg}$ for up 3 days after intervention. Cefuroxime concentration in cerebrospinal fluid is about $10 \%$ of that in plasma and the drug successfully treated meningitis caused by $\beta$-haemolytic streptococci, Streptococcus pneumoniae, and Neisseria meningitides, but when Salmonella species are the infective pathogens additional 5 mg dose is given intraventricularly. Some bacteria may become resistant to cefuroxime and antibiotic consumption is associated with increased bacterial-resistance. The aim of this study is to review the published data on cefuroxime and cefuroxime axetil dosing, efficacy, safety, and cefuroxime effects, prophylaxis, treatment, optimization, meningitis, pharmacokinetics and bacterial-resistance.
\end{abstract}

\section{Introduction}

This non-toxic broad-spectrum cefuroxime is one of the few cephalosporins that may be administered parenterally and orally. Cefuroxime is a $\beta$-lactamase resistant second-generation cephalosporin active against gram-positive organisms (including group B streptococci and penicillin-resistant staphylococci) and a wide range of gramnegative organisms. It is reasonable active against Haemophilus influenzae and Neisseria gonorrhoeae, but is inactive against Listeria, enterococci, Bacteroides, and Pseudomonas species. It has sometimes been used prophylactically in infants undergoing abdominal surgery Cefuroxime penetrates into the cerebrospinal poorly and coagulasenegative staphylococci are increasingly resistant to this antibiotic. Two-thirds of the lipophilic acetoxyethyl ester dose, cefuroxime axetil, is absorbed when is given orally, and after hydrolysis, it releases cefuroxime. There are no published reports of the use of this formulation in children aged<three months, but it has been widely used to treat otitis media and other respiratory infections in older children. It is just as active as treatment with co-amoxiclav and less likely causes troublesome loose stools. Cefuroxime is largely excreted by the kidney. Elimination half-life in plasma falls from six hours at birth to about three hours at two weeks. Infants aged $>$ one month clear cefuroxime from their plasma almost as fast as adults (half-life one hour), but dosage intervals should be extended in infants with severe renal failure. Toxic adverse-effects are rare but oral treatment does sometimes cause nausea and vomiting and a change in stool frequency, and pseudomembranous colitis has occasionally been reported. Other problems, as with cephalosporin in general, are uncommon. Lyme disease is caused by the spirochete Borrelia burgdorferi and human infection is caused by the bite of an infected animal tick. Illness was once rare in the United Kingdom but does not seem common in Europe and North America. While a migrating annular skin lesion (erythema migrans) is the classic presentation, symptoms are very variable. Foetal infection was first recognized in 1985 , and it is now realized that the risk to the foetus is comparable to that of congenital syphilis. Cefuroxime axetil is the antimicrobial agents of choice for early disease in young children. Intravenous ceftriaxone, cefotaxime, or benzylpenicillin are recommended if there are cardiac or neurological complications. The duration of treatment is usually two to four weeks $[1,2]$.

Cefuroxime inhibits bacterial cell wall in a manner similar to that of penicillin [3]. Peptidoglycan is a heteropolymeric component of the bacterial cell wall that provides rigid mechanical stability. $\beta$-Lactam antibiotics inhibit the last step in the peptidoglycan synthesis, the cell wall is 50 to 100 molecules thick in gram-negative bacteria and it is only 1 or 2 molecules thick in gram-negative organisms. The peptidoglycan is composed by glycan chains, which are linear strands of two alternating amino sugars ( $\mathrm{N}$-acetylglucosamine and $\mathrm{N}$-acetylmuramic) that are cross-linked by peptide chains. Peptidoglycan precursor formation takes place in the cytoplasm. The synthesis of UDP-acetylmuramylpentapeptide is completed with the addition of a dipeptide, D-alanyl-Dalanine (formed by racemization and condensation of L-alanine). UDP-

${ }^{*}$ Correspondence to: Gian Maria Pacifici, Associate Professor of Pharmacology, via Sant'Andrea 32, 56127 Pisa, Italy; E-mail: pacifici44@tiscali.it

Key words: cefuroxime, cefuroxime axetil, dosing, efficacy, safety, effects, prophylaxis, treatment, Lyme-disease, optimization, cerebrospinal fluidconcentration, plasma concentration, meningitis, pharmacokinetics, bacterialresistance, infants, children

Received: July 13, 2020; Accepted: July 21, 2020; Published: July 31, 2020 
acetylmuramyl-pentapeptide and UDP-acetylglucosamine are linked (with the release of the uridine nucleotides) to form a long polymer. The cross-link is completed by a transpeptidation reaction that occurs outside the cell membrane. The $\beta$-lactam antibiotics inhibit last step in peptidoglycan synthesis, presumably by acylating the transpeptidase via cleavage of the $-\mathrm{CO}-\mathrm{N}$ - bond of the $\beta$-lactam ring. The targets for the actions of $\beta$-lactam antibiotics are collectively termed penicillinbinding-proteins. The transpeptidase responsibly for synthesis of the peptidoglycan is one of these penicillin-binding-proteins. The lethality of penicillins for bacteria appears to involve both lytic and nonlytic mechanisms [2]. Cefuroxime has good activity against Haemophilus influenzae Neisseria meningitides and Streptococcus pneumonia. Activity against Escherichia coli and Klebsiella species is modest. Antistaphylococcal activity is inferior to first-generation cephalosporins. Unlike cefoxitin, cefotetan, and cefmetazole, cefuroxime lacks activity against Bacillus fragilis. Cefuroxime can be given orally, intravenously, or intramuscularly twice-daily to thrice-daily in children and adult patients. Concentrations in cerebrospinal fluid are about $10 \%$ of those in plasma, and the drug is effective but inferior to ceftriaxone for treatment of meningitis due to susceptible organisms [4].

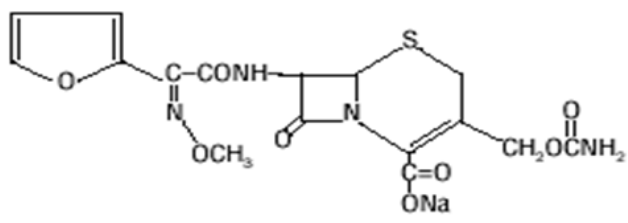

Molecular structure of cefuroxime (molecular weight=424 grams/ mole)

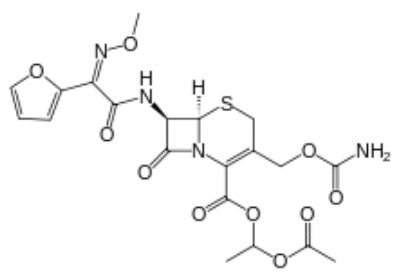

Molecular structure of cefuroxime axetil (molecular weight $=510$ grams/mole)

\section{Cefuroxime and cefuroxime axetil administration schedules in infants and children}

Cefuroxime and cefuroxime axetil admiration schedules in infants

Cefuroxime intravenous and intramuscular administration: give 25 $\mathrm{mg} / \mathrm{kg}$ twice-daily in the first week of life, thrice-daily in infants aged one to three weeks, and 4 times-daily in older infants. Dosage intervals need to be increased if there is serious renal failure [1].

Cefuroxime axetil oral administration: give 10 to $15 \mathrm{mg} / \mathrm{kg}$ (maximum per dose $=125 \mathrm{mg}$ ) orally twice-daily for mild to moderate infections. There is little experience of use in infants aged $<$ three months [1].

Cefuroxime administration schedules in children

Cefuroxime administrated orally

Children aged 3 months to 1 year: give $10 \mathrm{mg} / \mathrm{kg}$ twice-daily (maximum per dose $=125 \mathrm{mg}$ ) [3].

Children aged 2 to 11 years: give $15 \mathrm{mg} / \mathrm{kg}$ twice-daily (maximum per dose $=250 \mathrm{mg}$ ) [3].
Children aged 12 to 17 years: give $250 \mathrm{mg}$ twice-daily, and the dose intervals may be doubled for severe lower respiratory-tract infections and for pneumonia [3].

Cefuroxime administered parenterally

Give $20 \mathrm{mg} / \mathrm{kg}$ thrice-daily (maximum per dose $=750 \mathrm{mg}$ ); increase the dose up to $50-60 \mathrm{mg} / \mathrm{kg}$ thrice-daily or 4 times-daily (maximum per dose $=1.5$ grams), to treat severe infections and cystic fibrosis [3].

Cefuroxime administered orally to treat lower urinary-tract infection

Children aged 12 to 17 years: give $125 \mathrm{mg}$ twice-daily [3].

Cefuroxime administered by intravenous injection for surgical prophylaxis

Give $50 \mathrm{mg} / \mathrm{kg}$ (maximum per dose=1.5 grams) administered 30 min before procedure, then $30 \mathrm{mg} / \mathrm{kg}$ thrice-daily (maximum per dose $=750 \mathrm{mg}$ ) if required for up to three doses for high-risk procedures [3].

Cefuroxime axetil oral treatment schedules to treat Lyme disease

Children aged 3 months to 11 years: give $15 \mathrm{mg} / \mathrm{kg}$ twice-daily (maximum per dose $=500 \mathrm{mg}$ ) for 14 to 21 days (for 28 days to treat Lyme arthritis) [3].

Children aged 12 to 17 years: give $500 \mathrm{mg}$ twice-daily for 14 to 21 days (for 28 days to treat Lyme arthritis) [3].

\section{Literature search}

The literature search was performed electronically using PubMed database as search engine and the cut-off point was June 2020. The following key words: "cefuroxime infants effects", "cefuroxime children effects", "cefuroxime infants metabolism", "cefuroxime children metabolism", "cefuroxime infants pharmacokinetics", "cefuroxime children pharmacokinetics", "cefuroxime infants resistance", and "cefuroxime children resistance" were used. In addition, the books Neonatal Formulary [1], The British National Formulary for Children [3], and The Pharmacological Basis of Therapeutics [4] were consulted. The manuscript is written according to "Instructions for Authors".

\section{Results}

\section{Cefuroxime efficacy and safety in infants and children}

de Louvois [5] administered cefuroxime at a dose of $50 \mathrm{mg} /$ $\mathrm{kg}$ twice-daily for 5 days to 27 infected infants at birth and in early neonatal life. There was a significant improvement of symptoms and infants were discharged from hospital after 5 days of treatment, and cefuroxime was efficacy, safe, and well tolerated.

Powell et al. [6] assessed the efficacy, safety and tolerability of cefuroxime axetil suspension in 36 infants and children, aged 3 months to 12 years, and doses were: 10,15 , or $20 \mathrm{mg} / \mathrm{kg}$ twice-daily or thricedaily. Three of 36 patients (8.3\%) were withdrawn from therapy because of adverse-effects. Of 32 patients who completed therapy, 9 (28.1\%) developed mild-reactions including oral thrust, diarrhoea, or diaper dermatitis, and none were withdrawn from therapy. Complete clinical cure occurred in 28 subjects $(87.5 \%)$, and 4 subjects (12.5\%) were clinically improved but still required an additional antibiotic after one week to complete therapy, and treatment was effective, safety and well tolerated. 
Reed et al. [7] studied efficacy, safety and tolerability of cefuroxime axetil suspension in 35 children, aged 3 months to 12 years. The drug was administered at doses of: 10,15 , or $20 \mathrm{mg} / \mathrm{kg}$ twice-daily or thricedaily. Three of 35 subjects (8.6\%) were withdrawn from therapy because of drug-related reactions. Of 32 subjects who completed therapy, 9 (28.1\%) developed mild oral thrush, diarrhoea, or diaper dermatitis; bud none were withdrawn from therapy and this treatment was efficacy, safe, and well tolerated.

Barson et al. [8] treated 36 children, aged 3.5 to 4.7 years, suffering from infections in the face, epiglottis, or buccal cellulitis who were treated with cefuroxime at a dose of $75 \mathrm{mg} / \mathrm{kg}$ daily. Blood culture was performed in 22 children (61.1\%) and the infective pathogens were: Haemophilus influenzae type b, Streptococcus pneumoniae, and nontypable Haemophilus influenzae, and this treatment was efficacy and safe.

Syrogiannopoulos et al. [9] administered cefuroxime axetil at a dose of $250 \mathrm{mg}$ twice-daily for 10 days to 55 children, aged 5 to 11 years, suffering from acute otitis media. A tympanogram was obtained on enrolment and 2 days after completion of therapy. Complete cure occurred in $74.1 \%$ children and clinical improvement was observed in $25.9 \%$ children. There was no clinical failures and none children experienced relapse of acute otitis media infection one month after end of therapy.

Olivier [10] observed that treatment of community-acquired pneumonia caused by Mycoplasma, Chlamydia, or Legionella species required a drug which penetrates respiratory tissues effectively such as cefuroxime, and she reviewed literature on treatment of this disease. Cefuroxime axetil has been extensively used in infants aged $>3$ months, including those with pleural effusion complications or pneumonia; treatment duration was 24 to 72 hours, and therapy was successful.

\section{Cefuroxime effects in infants and children}

Burman et al. [11] observed that Enterobacter cloacae strains dominated aerobic flora in faeces of 79 of 953 infants (8.3\%) discharged from neonatal intensive care units. Cefuroxime yielded slight increase of MICs of ampicillin, cephalexin, and cephalothin compered to isolates obtained from untreated infants (P-value=0.02).

Zachariassen et al. [12] investigated cefuroxime pharmacokinetics in infants born to mothers undergoing caesarean section who received cefuroxime for prophylaxis. The drug migrated into infants and its plasma concentration and elimination half-life remarkably varied in infants.

Dierikx et al. [13] assessed the effect of cefuroxime on bacterial composition in gut of infants born to mothers treated with cefuroxime at single dose of 1.5 grams during, prior caesarean section and after umbilical clamping. Cefuroxime migrated into infants and impaired gut intestinal microbiota.

Arnez et al. [14] determined efficacy and adverse-effects caused by cefuroxime axetil administered at a dose of $30 \mathrm{mg} / \mathrm{kg}$ daily to 46 children, aged $<15$ years, suffering from erythema migrans. Efficacy and adverse-effects were compared to those of 44 children treated with phenoxymethyl penicillin at a dose of $100,000 \mathrm{IU} / \mathrm{kg}$ daily. Both treatments were equally efficacy, whereas adverse-effect-rates were: $26.1 \%$ and $6.8 \%$ (P-value=0.0301) following cefuroxime axetil and phenoxymethyl penicillin administration, respectively.

\section{Cefuroxime adverse-effects in children}

In literature there is only one study on adverse-effects caused by cefuroxime in children and it was reported by Gold and Rodriguez [15], they stated that cefuroxime is free from adverse-effects.

\section{Cefuroxime and cefuroxime axetil prophylaxis for urinary- tract infection and surgery in infants and children}

Gurevich et al. [16] observed that recurrent urinary-tract infections occurred in $19.8 \%$ infants, aged $<1$ month, and the first episode of infection occurred in 6 infants (5.9\%); peak incidence occurred 2 to 6 months after birth. One-hundred-one infants, aged $<2$ months, with the first and recurrent episodes of urinary-tract infections were treated with cefuroxime axetil. Infective pathogens were: Escherichia coli, Klebsiella species, Enterococcus species, Morganella morganii, Proteus and Enterobacter species. Prophylaxis significantly reduced the frequency of urinary-tract infection episodes up to $8.3 \%$.

Bitsori et al. [17] determined effects of prophylaxis in 638 uropathogens isolated from the urine of children. Infective uropathogens were: Escherichia coli, Klebsiella species, Pseudomonas aeruginosa, Enterococcus and Proteus species. Bacterial-resistancerate of these organisms to several antibiotics increased following their administrations, whereas that to cefuroxime decreased ( $\mathrm{P}$-value $<0.016$ ). Continuous surveillance, re-evaluation of empiric dosing regimens, and further assessment of prophylaxis are needed to optimize prophylaxis of urinary-tract infection.

Bi et al. [18] characterized pathogens and their antibiotic susceptibility in 895 isolated obtained from children with urinarytract infections caused by catheter indwelling in order to optimize prophylaxis. Escherichia coli was the most frequent pathogen, followed by Staphylococcus aureus, Staphylococcus epidermidis, and Enterococcus species. Gram-negative species were the predominant infective uropathogens and bacterial-susceptibility patterns must be determined in order to optimize prophylaxis.

Knoderer et al. [19] evaluated the efficacy of two prophylaxis regimens with cefuroxime in 210 children, aged $\leq 18$ years, undergoing cardiovascular surgery. Prolonged prophylaxis was performed before surgery and short-term prophylaxis was performed on the first day after intervention. Short-term post-operative prophylaxis did not increased infection outcomes.

\section{Cefuroxime treatment of infants and children}

Brogden et al. [20] stated that staphylococci $\beta$-lactamase producing and gram-negative bacteria are not resistant to ceftriaxone. This antibiotic was given parenterally to infants and children and effectively cured infections caused by gram-positive and gram-negative aerobes. Cefuroxime was also efficacy to treat respiratory infections caused by Haemophilus influenzae, Streptococcus pneumoniae, Klebsiella pneumoniae cephalosporin-resistant and Enterobacter.

Nelson et al. [21] Administered cefuroxime intravenously at a dose of $25 \mathrm{mg} / \mathrm{kg}$ thrice-daily to 100 infants, with mean age of 15 months, suffering from pneumoniae caused by Streptococcus pneumoniae, Haemophilus influenzae type b, Staphylococcus aureus, Neisseria meningitides B and pneumococcus species. All microorganisms were susceptible and had an MIC $\leq 1.25 \mu \mathrm{g} / \mathrm{ml}$. Mean duration treatment was 3.1 days in afebrile infants and 5.1 days until respiratory symptoms were gone. Eosinophilia occurred in only 10 infants (10.0\%), and cefuroxime successfully treat pneumonia. 
Pichichero [22] stated that antibiotic-resistance, caused by antecedent antibiotic treatment, is increasing in pathogens causing acute otitis media infections in infants. Amoxicillin is the first choice antibiotic to treat acute otitis media although a high dose of $80 \mathrm{mg} / \mathrm{kg}$ is needed to eradicate resistant-pathogens. Oral cefuroxime is a secondline antibiotic to treat this disease.

Shafina et al. [23] enrolled 101 infants and children, aged 1 day to 13 years, suffering from acute urinary-tract infections caused by Escherichia coli, Klebsiella and Enterococcus species which were treated with ampicillin. The resistance-rate to ampicillin was high for Escherichia coli, Klebsiella and Enterococcus whereas that to cefuroxime was low and cefuroxime is an appropriate antimicrobial agent for treatment of acute urinary-tract infections caused by these bacteria.

Wald [24] stated that Streptococcus pneumoniae, Haemophilus influenzae, and Moraxella catarrhalis are the commonest organisms causing acute and subacute sinusitis in infants and children. Amoxicillin is the appropriate treatment for infections caused by pathogens producing $\beta$-lactamase. If a patient does not respond to this treatment cefuroxime-axetil should be used as it has a broad-spectrum of activity.

\section{Cefuroxime administered to mothers before caesarean section causes alteration of microbiota composition in gut of their infants}

Kamal et al. [25] assessed alteration of microbiota in infant gut caused by cefuroxime prophylaxis performed in pregnant women undergoing caesarean section. Faecal samples were collected 10 days after birth and also after 9 months. Composition of gram-positive cocci and Enterobacteriaceae was assessed in infant gut born to these mothers. No alteration of microbiota composition was observed 10 days after birth whereas bacteria composition was altered 9 months later.

\section{Optimization of cefuroxime and cefuroxime axetil treatments in children}

Carlier et al. [26] optimized treatment with cefuroxime at a dose of $750 \mathrm{mg}$ thrice-daily in 20 critically ill children who had creatinine clearance $<20 \mathrm{ml} / \mathrm{min}$. Optimization of treatments were performed according to different cefuroxime dosing-regimens and also to creatinine clearance of: 50, 100, 200 and $300 \mathrm{ml} / \mathrm{min}$. Five-hundred children were simulated by Monte Carlo method for optimizing dosing-regimen which was defined as the blood concentration > MIC for at least $65 \%$ of dosing interval $\left(65 \% f \mathrm{~T}_{>\mathrm{MIC}}\right)$. Probability of attainment target-rates $\left(65 \% f \mathrm{~T}_{>\text {MIC }}\right)$ was calculated for each child and simulations were performed with the following cefuroxime MICs: 0.5 , $1,2,4,8$ and $16 \mu \mathrm{g} / \mathrm{ml}$. Simulations revealed that treatment failure occurred for organisms with an $\mathrm{MIC}=8 \mu \mathrm{g} / \mathrm{ml}$ when the cefuroxime was administered by intermittent infusion to children having renal clearance $\geq 50 \mathrm{ml} / \mathrm{min}$. Continuous infusion, with higher doses than the normal ones, achieved target-rates. However, even continuous infusions of cefuroxime at a dose of $\leq 9$ grams daily did not guarantee adequate blood concentrations for children with high creatinine clearance $\geq 300 \mathrm{ml} / \mathrm{min}$ when MIC was $8 \mu \mathrm{g} / \mathrm{ml}$.

Ibar-Bariain et al. [27] optimized dosing-regimens of cefuroxime axetil using Monte Carlo simulations in children. Optimal treatment was defined for cefuroxime axetil plasma concentrations $>$ MIC for at least $60 \%$ of dosing interval $\left(f \mathrm{~T}_{>\mathrm{MIC}} \geq 60 \%\right.$ ), and also for the cumulative fraction $\geq 90 \%$. Simulations revealed that cefuroxime axetil optimal dosing-regimens were: 10 to $15 \mathrm{mg} / \mathrm{kg}$ twice-daily infused over 0.5 hours for an $\mathrm{MIC} \leq 0.5 \mu \mathrm{g} / \mathrm{ml}$. However, for $\mathrm{MIC}=1 \mu \mathrm{g} / \mathrm{ml}$, only cefotaxime administered at a dose of $66 \mathrm{mg} / \mathrm{kg}$ thrice-daily ensured a probability of therapy success-rate $>90 \%$.

Pichichero et al. [28] used Monte Carlo simulations for optimizing dosing-regimens of $10 \beta$-lactamase resistant-antibiotics and assessed the probability of attaining pharmacodynamic target-rates in children suffering from recent respiratory infections caused by Haemophilus influenzae. Two-hundred-thirty-three isolates of Haemophilus influenzae were obtained from paediatric outpatients suffering from acute otitis media $(\mathrm{N}=55)$, sinusitis $(\mathrm{N}=58)$, and lower respiratory tract infections $(\mathrm{N}=120)$. Five-thousand concentration-time profiles were simulated for 10 antibiotics approved by US FDA including cefuroxime, using pharmacokinetic parameters and weights of male children aged 5 years. Optimal dosing regimen, against Haemophilus influenzae, was defined for cefuroxime unbound concentration in plasma $>$ MIC for $50 \%$ of the dosing interval $(50 \% f \mathrm{~T}>\mathrm{MIC})$. Sixty-seven isolates $(3.3 \%)$ were $\beta$-Lactamase producing and the infection sites were: acute otitis media $38 \%$, sinusitis $36 \%$, and lower respiratory-tract $21 \%$. Among 10 antibiotic tested, cefuroxime was the most active agent for prophylaxis and cure of children with acute otitis media caused by Haemophilus influenzae.

\section{Cefuroxime axetil treatment of lyme disease in children}

Lyme disease is caused by the bit of the spirochete Borrelia burgdorferi. Wormser et al. [29] reported guidelines for treatment of Lyme disease in children. Suggested treatments were cefuroxime axetil at a dose of $15 \mathrm{mg} / \mathrm{kg}$ twice-daily (maximum $500 \mathrm{mg}$ ) for 14 to 21 days. Recommended duration of treatments was for: erythema migrans (14 to 21 days), acute neurological disease, meningitis, radiculopathy or cranial-nerve (14 to 28 days), cardiac disease $1^{\text {st }}$ and $2^{\text {nd }}$ degree (14 to 31 days), $3^{\text {rd }}$ degree (14 to 213 days), and arthritis (14 to 28 days). Occurrence-rates of the first and multiple lesions of erythema migrans were: 98.3 and $16.8 \%$, respectively, in subjects treated with cefuroxime axetil and the size of the primary lesion was $79+10 \mathrm{~cm}^{2}$ [30]. Gerber et al. [31] reported the frequency of treatment for infections caused by Borrelia burgdorferi bit and was: fever $24 \%$, fatigue $58 \%$, headache $42 \%$, arthralgia $33 \%$, neck pain $26 \%$, nausea $21 \%$, abdominal pain $17 \%$, diarrhoea $16 \%$, myalgia $16 \%$, sore throat $12 \%$, cough and rhinorrhoea $8 \%$, vomiting and conjunctivitis $5 \%$.

\section{Ceftriaxone penetration into the cerebrospinal fluid of infants and children}

Rochette [32] measured the cerebrospinal volume in 54 preterm and term infants, with a postmenstrual age of 30 to 60 weeks, and the volume was $1.97+0.54 \mathrm{ml} / \mathrm{kg}$. The Pearson's rank correlation test revealed that cerebrospinal fluid volume correlated with both the infant weight and the postmenstrual age $(\mathrm{r}=0.78, \mathrm{P}$-value $<0.0001)$.

Pfenninger et al. [33] enrolled 33 infants, aged $>3$ months, suffering from meningitis caused by: Haemophilus influenzae, Neisseria meningitides, and Streptococcus pneumoniae. Cefuroxime was intravenously infused at a dose of $50 \mathrm{mg} / \mathrm{kg} 4$ times-daily, the duration of treatment was 12 to 13 days, and cerebrospinal fluid concentration ranged from 1.1 to $18.8 \mu \mathrm{g} / \mathrm{ml}$ (mean, 7.0).

Edwards et al. [34] studied 7 children, aged 7 months to 9 years, suffering from meningitis caused by Staphylococcus epidermis, Staphylococcus aureus, Staphylococcus hominis, and Staphylococcus sciuri. Cefuroxime was intravenously infused at doses of 67 and $76 \mathrm{mg} /$ $\mathrm{kg}$ thrice-daily for 2 to 14 days; cefuroxime crossed the brain blood 
barrier easily and achieved concentrations from $<2.0$ to $22.5 \mu \mathrm{g} / \mathrm{ml}$ in cerebrospinal fluid. The wide interindividual variability of cefuroxime concentration reflected both the site of local inflammation and the time after dosing.

Kuzemko and Walker [35] measured cefuroxime concentration in cerebrospinal fluid of 6 children, aged 1.5 to 6 years, with meningitis caused by Neisseria meningitides (MIC $=0.025 \mu \mathrm{g} / \mathrm{ml}$ ), Haemophilus influenzae $(\mathrm{MIC}=0.5 \mu \mathrm{g} / \mathrm{ml}$ ), and Streptococcus pneumoniae (MIC was not determined). Cefuroxime was intravenous infused at a dose of $25 \mathrm{mg} / \mathrm{kg}$ twice-daily in three children and other 3 children received this drug by lumbar puncture. Cefuroxime concentration ranged from 1.5 to $6.0 \mu \mathrm{g} / \mathrm{ml}$ in cerebrospinal fluid and was > MICs for Neisseria meningitides and Haemophilus influenzae indicating that cefuroxime is an appropriate antimicrobial agent to cure meningitis caused by these organisms.

\section{Ceftriaxone treatment of bacterial meningitis in infants and children}

Sirinavin et al. [36] intravenously infused cefuroxime at a dose of $50 \mathrm{mg} / \mathrm{kg}$ daily for 14 to 15 days to 7 infants and children, aged 25 days to 12 years, suffering from meningitis caused by $\beta$-haemolytic streptococci, Streptococcus pneumoniae, Neisseria meningitides, Salmonella krefeld and Salmonella typhimurium. Cerebrospinal fluid and blood specimens were sampled 2 hours after dosing after the fourth or successive treatment days. Other 6 infants were suffering from meningitis caused by Haemophilus influenzae and all were cured. Five infants of these were initially treated with cefuroxime co-administered with penicillin bud cefuroxime treatment was discontinued after two days because etiological agents were: hospital-acquired Pseudomonas cepacia and Pseudomonas aeruginosa strains which are cefuroximeresistant. Cefuroxime concentration was measured in cerebrospinal fluid and serum of other 9 subjects on the second treatment day and was: $6.4+1.7$ and $35.5+9.5 \mu \mathrm{g} / \mathrm{ml}$, respectively, and the ratio was $18.8+3.0 \%$. Cefuroxime concentration was also measured in cerebrospinal fluid and plasma of 6 subjects on the 14th treatment day and was: $3.6+2.2$ and $32.2+23.3 \mu \mathrm{g} / \mathrm{ml}$, respectively, and the ratio was $12.1+2.5 \%$. In children without meningitis, cefuroxime concentrations were: $1.3+1.3$ and $32.5+14.7 \mu \mathrm{g} / \mathrm{ml}$, in cerebrospinal fluid and serum, respectively, and the ratio was $3.8+2.4 \%$. Cerebrospinal fluid concentration was $>10$ fold higher than the MICs of $\beta$-haemolytic streptococci, Streptococcus pneumoniae, Haemophilus influenzae, Streptococcus pneumoniae, and Neisseria meningitides, whereas MICs of Salmonella strains were similar to those of cefuroxime. Meningitis caused by $\beta$-haemolytic streptococci, Streptococcus pneumoniae, Neisseria meningitides and Haemophilus influenzae type b, was cured with $50 \mathrm{mg} / \mathrm{kg}$ cefuroxime given 4 timesdaily, whereas meningitis caused by Salmonella species required an additional dose of $5 \mathrm{mg}$ cefuroxime injected intraventricularly for 4 days. Other ten subjects without meningitis received single cefuroxime dose of $50 \mathrm{mg} / \mathrm{kg}$ and cerebrospinal fluid concentration was 3 to 6 times lower than those measured in subjects with meningitis, thus inflamed meninges improve cefuroxime penetration-rate into cerebrospinal fluid.

Del Rio et al. [37] evaluated susceptibility of Haemophilus influenzae, Neisseria meningitides, and Streptococcus pneumoniae to cefuroxime in 38 infants and children, aged $1.3+1.3$ years (range, 4 weeks to 6.5 years), suffering from meningitis. Twenty-seven subjects (71.0\%) had meningitis caused by Haemophilus influenzae type b, $(\beta$-lactamase negative and $\beta$-lactamase positive), Haemophilus influenza type e $\beta$-lactamase-negative, Streptococcus pneumoniae, Neisseria meningitides, and group B Streptococcus, whereas 4 subjects were not infected. Cefuroxime plasma concentration was measured after single daily intravenous doses of 50 and $75 \mathrm{mg} / \mathrm{kg}$ of cefuroxime for a minimum of 5 days in 5 children. Table 1 shows susceptibility of bacteria to cefuroxime. Cefuroxime plasma concentration correlated with the protein content following a dose of $50 \mathrm{mg} / \mathrm{kg}(\mathrm{P}$-value=0.01) and $75 \mu \mathrm{g} / \mathrm{ml}$ (P-value=0.039), and the concentration was higher following $75 \mathrm{mg} / \mathrm{kg}$ at each time interval. Mean cefuroxime exposition in cerebrospinal fluid, expressed as the AUC in cerebrospinal fluid to that in plasma ratio, ranged from 6.4 to $10.0 \%$ following 50 and $75 \mathrm{mg} /$ $\mathrm{kg}$ doses, respectively. Cefuroxime concentration $(\mu \mathrm{g} / \mathrm{ml})$ was measured in cerebrospinal fluid on the first and $6^{\text {th }}$ doses at various times after administration and was respectively: 0.96 and 2.1 at 0.5 hours, 17.3 and 14.5 at 1 hour, 2.5 and 3.4 at 2 hours, and 2.1 and 0.94 at 4 hours. Both MICs and MBCs tested for these 5 organisms were lower than cefuroxime concentrations in cerebrospinal fluid suggesting that this drug is an appropriate antimicrobial agent to treat bacterial meningitis caused by these organisms.

\section{Cefuroxime plasma and serum concentrations in infants}

Philipson and Stiernstedt [38] measured cefuroxime plasma concentration in infants at birth, born to mothers who received cefuroxime at a dose of $750 \mathrm{mg}$, and it ranged from 1.4 to $3.6 \mu \mathrm{g} / \mathrm{ml}$. Reference 5 is above reported under the heading cefuroxime efficacy and safety. de Louvois [5] measured cefuroxime serum concentration in 28 preterm and term infants with a body weight of $2.0+0.85 \mathrm{~kg}$ who received cefuroxime parenterally at a dose of $25 \mathrm{mg} / \mathrm{kg}$ twice-daily. Median concentrations were: $35,45,42,35,26$, and $10.5 \mu \mathrm{g} / \mathrm{ml}$ at: 0.25 , $0.5,1,3,5,12$ hours after dosing, and the median elimination half-life was $6.0+2.1$ hours.

\section{Cefuroxime pharmacokinetics in infants undergoing cardio pulmonary bypass}

Gertler et al. [39] studied cefuroxime pharmacokinetics in 42 infants, aged $<1$ year, of whom 36 had congenital heart defect and underwent cardio pulmonary bypass, whereas 6 did not. Cefuroxime single dose of $50 \mathrm{mg} / \mathrm{kg}$ was intravenously infused before cardio pulmonary bypass and $75 \mathrm{mg} / \mathrm{kg}$ was injected in the prime volume. The impact of age (Fmat) on total body clearance had a sigmoid maturation function and was calculated according to the following equation:

$$
\text { Fmat=PMA }{ }^{\mathrm{HILL}} /\left(\mathrm{PMS}^{\mathrm{HILL}}+\mathrm{PMA}_{50}{ }^{\mathrm{HILL}}\right)
$$

Table 1. Susceptibility of 5 bacteria to cefuroxime which were isolated from to cerebrospinal fluid. Susceptibility is expressed as both the minimum inhibitory concentration (MIC) and the minimum bactericidal concentration (MBC). Figures are the range and (median), by Del Rio et al. [37]

\begin{tabular}{|c|c|c|c|}
\hline Strain tested & Number of isolates & MIC $(\boldsymbol{\mu g} / \mathbf{m l})$ & MBC $(\boldsymbol{\mu g} / \mathbf{m l})$ \\
\hline Haemophilus influenzae $\beta$-lactamase negative & 26 & $0.156-0.625(0.312)$ & $0.312-0.625(0.312)$ \\
\hline Haemophilus influenzae $\beta$-lactamase positive & 7 & $0.312-0.625(0.312)$ & $<0.02-0.05$ \\
\hline Neisseria meningitis & 3 & $0.02-0.156$ & $0.02-1.0$ \\
\hline Streptococcus pneumoniae & 2 & $0.02-0.156$ & 0.312 \\
\hline Group B streptococcus & 1 & 0.625 \\
\hline
\end{tabular}


Where: $\mathrm{PMA}=$ postmenstrual age, HILL=HILL coefficient, and $\mathrm{MPA}_{50}=$ the maturation half-life.

Peak cefuroxime total and unbound plasma concentrations were: $271+62$ and $229+52 \mu \mathrm{g} / \mathrm{ml}$, respectively, before cardio pulmonary bypass (dose $=50 \mathrm{mg} / \mathrm{kg}$ ), and those after the second dose $(75 \mathrm{mg} / \mathrm{kg}$ ) were: $404+102$ and $341+86 \mu \mathrm{g} / \mathrm{ml}$, respectively. Table 2 shows cefuroxime pharmacokinetic population parameters. The peripheral distribution volume is larger than the central distribution volume indicating that cefuroxime well distributes in body tissues.

\section{Cefuroxime pharmacokinetics in infants and children}

Reference 37 is above reported under the heading cefuroxime penetration into the cerebrospinal fluid. Del Rio et al. [37] investigated cefuroxime pharmacokinetics in plasma of 5 infants and children on the first and 6th treatment days. Cefuroxime was intravenous infused at doses of 50 and $75 \mathrm{mg} / \mathrm{kg}$. Following a dose of $50 \mathrm{mg} / \mathrm{kg}$, plasma concentrations $(\mu \mathrm{g} / \mathrm{ml})$ were: $105+36$ at the end of infusion and $4.4+4.5$ 6 hours later, and after a dose of $75 \mathrm{mg} / \mathrm{kg}$, these concentrations were: $152+43.5$ and $5.4+3.0$, respectively. Table 3 summarizes pharmacokinetic parameters obtained in 5 subjects following multiple cefuroxime dosing of $50 \mathrm{mg} / \mathrm{kg}$, on the first and the $6^{\text {th }}$ administration days. Absorption and elimination half-live, distribution volume, and the total body clearance are not statistically different according the two sampling days suggesting that cefuroxime does not accumulate in blood.

Powell et al. [40] assessed cefuroxime axetil pharmacokinetics in 28 infants and children, aged 3 months to 12 years (mean, 1.2 years) with bacterial infection, and were treated with a single cefuroxime axetil suspension at doses of 10,15 , or $20 \mathrm{mg} / \mathrm{kg}$. Table 4 shows that cefuroxime axetil serum peak concentrations were not statistically different according to the 3 doses. In addition, Tmax, AUC, and elimination half-life are not statistically different according the dosages indicating that cefuroxime axetil pharmacokinetic parameters are not dosing-dependent.

\section{Cefuroxime pharmacokinetics in children undergoing cardio pulmonary bypass}

Knoderer et al. [41] assessed cefuroxime pharmacokinetics in 16 children, aged $1.2+0.3$ years with a body-weight of $9.7+2.8 \mathrm{~kg}$, requiring cardio pulmonary bypass for cardiac surgical repair. Cefuroxime was intravenously infused at a dose of $25 \mathrm{mg} / \mathrm{kg}$ one hour before skin incision and another dose of $12.5 \mathrm{mg} / \mathrm{kg}$ was injected in the cardio pulmonary bypass prime fluid. The distribution volume of the peripheral compartment was similar to that of the central compartment and this contrasts with the results obtained in infants undergoing cardio pulmonary bypass in whom peripheral distribution volume is larger than the central distribution volume [39]. Likely, total protein content is lower in plasma of infants than that of children, thus the extent of cefuroxime bound plasma proteins is lower in infants with consequent higher migration-rate into body-tissues causing a larger peripheral distribution volume.

\section{Mechanisms bacterial-resistance to cefuroxime}

Källman et al. [42] determined cefuroxime susceptibility by discdiffusion and by E-test methods. The ability of bacteria to grow in

Table 2. Cefuroxime final population pharmacokinetic parameters obtained in 36 infants undergoing cardiopulmonary bypass, whereas 6 infants did not. Parameters are estimated for the entire population of 42 infants who were aged < 1 year; figures are the typical value (\%RSE) median, and \%relative standard error (\%RSE), by Gertler et al. [39]

\begin{tabular}{|c|c|c|c|c|}
\hline & \multicolumn{4}{|c|}{ Parameters estimated in all 42 infants } \\
\hline & Typical value (\%RSE) & \%RSE & Bootstrap: median (\%RSE) & $\%$ RSE \\
\hline \multicolumn{5}{|c|}{ Individual parameters } \\
\hline${ }^{*}$ Central distribution volume $(\mathrm{L} / \mathrm{kg})$ & $11.2(8.3)$ & $0.178(10.3)$ & $11.3(8.8)$ & $0.170(10.4)$ \\
\hline $\begin{array}{l}\text { *Peripheral distribution volume } \\
(\mathrm{L} / \mathrm{kg})\end{array}$ & $17.1(4.2)$ & $0.037(1.1)$ & $17.1(4.3)$ & $0.037(13.5)$ \\
\hline *Total body clearance $(\mathrm{L} / \mathrm{kg})$ & $3.1(6.4)$ & $0.048(1.2)$ & $5.1(9.1)$ & $0.046(13.0)$ \\
\hline HILL coefficient & $4.1(24)$ & --- & $4.7(39.1)$ & --- \\
\hline Elimination rate constant $\left(\mathrm{L} \cdot \mathrm{h}^{-1}\right)$ & $18.2(9.5)$ & $0.093(3.7)$ & $168(10.5)$ & \\
\hline $\begin{array}{l}\text { Residual variability, additive error } \\
\text { model }(\mu \mathrm{g} / \mathrm{ml})\end{array}$ & $17.9(7.6)$ & --- & $17.7(7.8)$ & --- \\
\hline
\end{tabular}

*Parameters corrected for $70 \mathrm{~kg}$ body-weight. \%RSE=percent relative standard error.

Table 3. Cefuroxime pharmacokinetic parameters obtained in plasma of 5 infants and children following cefuroxime single and multiple doses of $50 \mathrm{mg} / \mathrm{kg}$. Values are reported according to the first and $6^{\text {th }}$ dose. Figures are the mean+SD, by Del Rio et al. [37]

\begin{tabular}{|c|c|c|c|c|c|}
\hline \multirow[b]{2}{*}{ Dose $(50 \mathrm{mg} / \mathrm{kg})$} & \multicolumn{2}{|c|}{ Half-life (hours) } & \multirow[b]{2}{*}{$\begin{array}{c}\text { Distribution volume (L/ } \\
\text { kg) }\end{array}$} & \multirow[b]{2}{*}{$\begin{array}{l}\text { Total body clearance }(\mathrm{ml} / \mathrm{min} .1 .73 \\
\left.\mathrm{m}^{2}\right)\end{array}$} & \multirow[b]{2}{*}{$\operatorname{AUC0}-\infty(\mu . h / m l)$} \\
\hline & Absorption & Elimination & & & \\
\hline First dose & $0.30 \pm 0.03$ & $1.8 \pm 0.4$ & $0.60 \pm 0.08$ & $141 \pm 60$ & $233 \pm 79$ \\
\hline $6^{\text {th }}$ dose & $0.16 \pm 0.03$ & $1.7 \pm 0.3$ & $0.60 \pm 0.15$ & $131 \pm 60$ & $215 \pm 85$ \\
\hline *Value & 0.5000 & 0.4124 & 0.5000 & 0.4124 & 0.4124 \\
\hline
\end{tabular}

*Mann Whitney test

Table 4. Pharmacokinetics of cefuroxime was assessed following 10, 15, or $20 \mathrm{mg} / \mathrm{kg}$ single oral dose of cefuroxime axetil. Pharmacokinetic parameters were obtained in 28 infants and children aged 3 months to 12 hear (mean, 1.9 years). Figures are the mean + SD, by Powell et al. [40]

\begin{tabular}{|c|c|c|c|c|c|}
\hline Dose and N. of subjects & $\operatorname{Cmax}(\mu \mathrm{g} / \mathrm{ml})$ & Tmax (hours) & $\operatorname{AUC0}-\infty\left(\mu \mathrm{g}^{*} \mathrm{~h} / \mathrm{ml}\right)$ & Elimination half-life (hours) & $* *$ Time for conc. $>1 \mu \mathrm{g} / \mathrm{ml}$ \\
\hline $10 \mathrm{mg} / \mathrm{kg}, \mathrm{N}=8$ & $3.3 \pm 0.8$ & $3.6 \pm 1.4$ & $12.4 \pm 2.5$ & $1.9 \pm 0.7$ & $4.2 \pm 0.6$ \\
\hline $15 \mathrm{mg} / \mathrm{kg}, \mathrm{N}=12$ & $5.1 \pm 1.4$ & $2.7 \pm 1.1$ & $22.5 \pm 9.3$ & $1.4 \pm 0.7$ & $5.9 \pm 1.3$ \\
\hline $20 \mathrm{mg} / \mathrm{kg}, \mathrm{N}=8$ & $7.0 \pm 2.0$ & $3.1 \pm 1.6$ & $32.8 \pm 10.2$ & $1.9 \pm 1.6$ & $6.6 \pm 1.0$ \\
\hline *P-value & --- & 0.9551 & --- & 0.7465 & 0.8601 \\
\hline
\end{tabular}

*Kruskal-Wallis test. **Time during which serum concentration $>1 \mu \mathrm{g} / \mathrm{ml}$. 
Table 5. Cefuroxime pharmacokinetic parameters are obtained in 16 children, aged $1.2 \pm 0.3$ years (body-weight $=9.7 \pm 2.8 \mathrm{~kg}$ ), undergoing cardio pulmonary bypass. Cefuroxime was intravenously infused at a dose of $25 \mathrm{mg} / \mathrm{kg} 1$ hour before skin incision and another dose of $12.5 \mathrm{mg} / \mathrm{kg}$ was given in the cardio pulmonary bypass prime solution. Figures are the mean+SD, by Knoderer et al. [41]

\begin{tabular}{|c|c|}
\hline Pharmacokinetic parameters & Mean \pm SD \\
\hline Distribution clearance between the central and peripheral compartment $(\mathrm{ml} / \mathrm{min} / \mathrm{kg})$ & $43.9 \pm 40.2$ \\
\hline$*$ Total body clearance $(\mathrm{ml} / \mathrm{min} / \mathrm{kg})$ & $11.8 \pm 4.79$ \\
\hline *Apparent distribution volume in the peripheral compartment $(\mathrm{L} / \mathrm{kg})$ & $8.08 \pm 4.49$ \\
\hline$*$ Apparent distribution volume in the central compartment $(\mathrm{L} / \mathrm{kg})$ & $8.53 \pm 3.72$ \\
\hline *Apparent distribution volume at steady-state $(\mathrm{L} / \mathrm{kg})$ & $0.210 \pm 0.060$ \\
\hline Half-life (hours) & $19.1 \pm 3.51$ \\
\hline Absorption half-life $($ hours $)$ & $0.037 \pm 0.006$ \\
\hline Peak concentration obtained at the first dose $(\mu \mathrm{g} / \mathrm{ml})$ & $328 \pm 102$ \\
\hline
\end{tabular}

presence of organic solvents was assessed as a phenotypically measure of efflux. Cefuroxime susceptibility was also determined in presence of a known efflux pump inhibitor MC-207,110. Escherichia coli strains, that were organic solvent tolerant, had higher MIC values (4 to $>256 \mu \mathrm{g} / \mathrm{ml}$; median, 24) than non-tolerant strains. In strains with most pronounced organic solvent-tolerance (i.e. cyclohexane-tolerant strains) cefuroxime MICs were decreased by 2 -fold (P-value $<0.03$ ) supporting the hypothesis that efflux pump contributes to cefuroxime resistance in Escherichia coli.

Källman et al. [43] studied whether efflux or down-regulation of porins contributes to cefuroxime resistance in Klebsiella pneumoniae. Transcription-rate of acrA, ompK35, ramA, and soxS was determined by quantitative RT-PCR. All clinical isolates had similar non-susceptibility to cefuroxime. Phenylalanine arginine $\beta$-naphthylamide did not increase susceptibility to cefuroxime. Increased acrA transcriptionrate and decreased ompK35 transcription-rate was seen in all strains. Multidrug-resistant phenotype of Klebsiella pneumoniae is associated with increased acrA and ramA gene transcription-rate and decreased ompK35 gene transcription-rate. Since cefuroxime resistance was not reversed by $\beta$-naphthylamide, this is attributable to decreased levels of OmpK35 rather than to efflux.

Alam et al. [44] reported the occurrence of antibiotic-resistance and production of $\beta$-lactamases including expended-spectrum $\beta$-lactamases in enteric bacteria isolated from hospital wastewater. Among 69 isolates tested for antibiotic sensitivity, $73.9 \%$ strains had cefuroxime-resistantrate of $39.1 \%$. MIC showed a high resistance-level (800 to $1,600 \mu \mathrm{g} / \mathrm{ml})$ and 63 isolates $(91.3 \%)$ produced $\beta$-lactamase. Multidrug-resistancerate observed for cefuroxime was $18.8 \%$ and 15 isolates $(21.7 \%)$ were extended-spectrum $\beta$-lactamases producing. Four extended-spectrum $\beta$-lactamase producing organisms (5.8\%) could transfer their R-plasmid to the recipient strain of Escherichia coli K-12 with conjugation frequency ranging from $7.0^{\star} 10^{-3}$ to $8.8^{\star} 10^{-4}$. Enteric bacteria extendedspectrum $\beta$-lactamase producing is common in the wastewater, and such isolates may disseminate multidrug-resistance caused by genetic exchange mechanisms and requires immediate attention.

Gunduz and Altun [45] evaluated causative pathogens and their antibiotic-resistance in 850 positive strains isolated from the urine of children aged 3.0+3.7 years. Commonest causative pathogens were: Escherichia coli (64.2\%) followed by Klebsiella pneumoniae (14.9\%). Overall resistance-rate to three antibiotics ranged from 62.6 to $29.8 \%$ and that to cefuroxime was $28.7 \%$. Escherichia coli was the commonest bacteria isolated which had the highest resistance-rate to cefuroxime. Several authors observed that antibiotic consumption including cefuroxime was associated with measurable and statistical significant increase in the resistance-rate [46-48].

\section{Discussion}

Cefuroxime is a second-generation cephalosporin $\beta$-lactamase resistant which is active against gram-positive and most gramnegative organisms, and bacteria highly sensitive to cefuroxime are: Haemophilus influence (even strains ampicillin-resistant), Neisseria meningitides, and Streptococcus pneumoniae. Cefuroxime is available for oral, intravenous, and intramuscular administration; it is rapidly absorbed when given by mouth, the gastrointestinal absorption-rate of the prodrug cefuroxime axetil is $70 \%$, and after hydrolysis it releases cefuroxime $[1,3]$. Cefuroxime and cefuroxime axetil are efficacy and safe in infants and children [5-10] and adverse-effects do not occur even when high doses are given [15]. Parenteral dosing-regimens consist of $25 \mathrm{mg} / \mathrm{kg}$, twice-daily, thrice-daily or 4-times-daily and dose intervals decrease with infant maturation [1]. Oral dosing-regimens are: $10,15 \mathrm{mg} / \mathrm{kg}$ and $250 \mathrm{mg}$ for children aged up to 1 year, 2 to 11 and 12 to 17 years, respectively-tract [3]. Prophylaxis reduces the frequency of infection episodes of urinary-tract $[3,23]$ and respiratory infections [20], surgery [16-19], pneumonia [21] acute otitis media [22], and sinusitis [24], and it has been used to decrease bacteria burden before surgery [6-19]. Cefuroxime axetil is the drug of choice for treatment of erythema migrans [14] and Lyme disease [29]. Treatment with cefuroxime has been used to treat generalized infections [20], urinarytract infections [22, 23], and also pneumonia [21], and sinusitis [24], caused by gram-negative and gram-positive organisms. Optimization of dosing-regimens consists in maintaining cefuroxime plasma concentrations above MICs of infective pathogens for at least $50 \%$ to $60 \%$ of dosing intervals [26-28]. Cefuroxime crosses the brain-bloodbarrier easily and concentration in cerebrospinal fluid is about $10 \%$ of that in plasma [32-35], and successfully treated meningitis caused by $\beta$-haemolytic streptococci, Streptococcus pneumonia, and Neisseria meningitides [36,37], whereas meningitis caused by Salmonella species requires an additional dose of $5 \mathrm{mg}$ injected intraventricularly. Cefuroxime pharmacokinetics have been assessed in infants [39], in infants and children [37,41] and those, following cefuroxime axetil administration have been reported in infants and children [40] Cefuroxime half-life is 1.8 hours in children aged up to 6 years [37] and 6 hours in infants during the first week of life [38]. Following three doses of cefuroxime axetil, cefuroxime $\mathrm{Cmax}$ and $\mathrm{AUC}_{0-\infty}$ were not statistically different indicating that cefuroxime does not accumulate in blood [40]. Consistent results were obtained following cefuroxime administration on the first and $6^{\text {th }}$ dose, thus cefuroxime does not accumulate in blood even for prolonged treatment [37]. Distribution volume of cefuroxime is $0.60 \mathrm{~L} / \mathrm{kg}$ in infants and children; thus it migrates into body tissues in relevant amounts and diffuses in more than one half of the body volume [37]. Escherichia coli $[42,44,45]$ and Klebsiella pneumoniae $[43,45]$ may become cefuroxime-resistant; efflux pump [42] is responsible for increased-resistance of Escherichia coli [42] whereas resistance of Klebsiella pneumonia is caused by increased 
transcription-rates of acrA, ramA genes and decreased transcriptionrate of the gene OmpK35 [43]. Multidrug-resistant of Enteric extendedspectrum $\beta$-lactamase producing organism to cefuroxime has been observed in about $20 \%$ of isolates. Resistance is caused by genetic exchange mechanisms, consequently disseminate multidrug-resistance, and requires immediate attention [44]. Cefuroxime consumption is associated with increased bacteria resistance [46-48], continuous surveillance of resistance-rates and antibiotic consumption are of utmost importance for optimizing antibiotic dosing strategy.

In conclusion, cefuroxime is a second-generation cephalosporin $\beta$-lactamase resistant; it inhibits bacterial cell wall synthesis of grampositive and gram-negative organisms, and is rapidly bactericidal. Administration forms are available for oral and parenteral administrations, cefuroxime is rapidly absorbed when given orally, and the absorption-rate of the prodrug cefuroxime axetil is about $70 \%$. Cefuroxime axetil works by realising cefuroxime after hydrolysis. Oral administration of cefuroxime and cefuroxime axetil yields high blood concentrations ensuring eradication of pathogenic microorganisms. These drugs, even given at high doses, do not cause adverse-effects. Cefuroxime axetil is the drug of choice to treat erythema migrans [14] and Lyme [29] diseases. Cefuroxime has been found efficacy against infections caused by gram-negative and gram-positive bacteria. Cefuroxime elimination half-live are: 6 hours in infants during the first week of life and 1.8 hours in children aged up to 6 years. Cefuroxime penetrates into the cerebrospinal fluid where achieves a dose of about $10 \%$ of that in plasma concentration, and successfully treated meningitis caused by $\beta$-haemolytic streptococci species, Haemophilus influenzae, and Neisseria meningitides, whereas meningitis caused by Salmonella species requires an additional dose of $5 \mathrm{mg}$. Some bacteria, including Escherichia coli and Klebsiella pneumoniae, may became cefuroximeresistant, and antibiotic consumption, including cefuroxime, is associated with increased resistance, and judicious use of this antibiotic ensures efficacy against bacteria.

\section{Conflict of interests}

The authors declare no conflicts of financial interest in any product or service mentioned in the manuscript, including grants, equipment, medications, employments, gifts, and honoraria.

This article is a review and drugs have not been administered to men or animals.

\section{Acknowledgments}

The author thanks Dr. Patrizia Ciucci and Dr. Francesco Varricchio, of the Medical Library of the University of Pisa, for retrieving the scientific literature.

\section{References}

1. Neonatal Formulary. Cefuroxime, 8th Edition, 2020, Oxford University Press. Great Clarendon Street, Oxford, OX2, 6DP, UK, pp: 189-191.

2. Bayles KW (2000) The Bactericidal Action of Penicillin: New Clues to an Unsolved Mystery. Trends Microbiol 8: 274-278. [Crossref]

3. British national formulary for children (2020) Cefuroxime. 78th Edition, Macmillan, Hampshire International Business Park, Hampshire, Lime Three Way, Basingstoke, Hampshire, UK, pp: 329-330.

4. MacDougal C (2019) Penicillins, Cephalosporins, and other $\beta$-Lactam Antibiotics. In the Goodman \& Gilman's. The Pharmacological Basis of Therapeutics. 13th Edition. Brunton Hilal-dandan LL, Knollmann BC, editors. Mc Graw Hill, New York, pp: 10331035.5 .

5. de Louvois J, Mulhall A, Hurley R (1982) Cefuroxime in the treatment of neonates. Arch Dis Child 57: 59-62. [Crossref]
6. Powell DA, Nahata MC, Powell NE, Ossi MJ (1991) The safety, efficacy, and tolerability of cefuroxime axetil suspension in infants and children receiving previous intravenous antibiotic therapy. DICP 25: 1236-1238. [Crossref]

7. Barson WJ, Miller MA, Marcon MJ, Hribar MM, Brady MT, et al. (1985) Cefuroxime therapy for bacteremic soft-tissue infections in children. Am J Dis Child 139: 11411144. [Crossref]

8. Syrogiannopoulos GA, Goumas FA, Haliotis CG, Lygatsikas CD, Beratis NG (1992) Cefuroxime axetil in the treatment of acute otitis media in children. $J$ Chemother 4 : 221-224. [Crossref]

9. Olivier C (2000) Clinical use of cefuroxime in paediatric community-acquired pneumonia. Paediatric Drugs 2: 331-343. [Crossref]

10. Burman LG, Berglund B, Huovinen P, Tullus K (1993) Effect of ampicillin versus cefuroxime on the emergence of beta-lactam resistance in faecal enterobacter cloacae isolates from neonates. J Antimicrob Chemother 31: 111-116.

11. Zachariassen G, Hyldig N, Joergensen JS, Nielsen DS, Greisen G (2016) The half-life and exposure of cefuroxime varied in newborn infants after a caesarean section. Acta Paediatr 105: 1074-1078.

12. Dierikx TH, Berkhout DJC, Visser L, Benninga MA, Roeselers G, et al. (2019) The influence of timing of maternal administration of antibiotics during cesarean section on the intestinal microbial colonization in infants (mami-trial): study protocol for a randomised controlled trial. Trials 20: 479. [Crossref]

13. Arnez M, Radsel-Medvescek A, Pleterski-Rigler D, Ruzić-Sabljić E, Strle F (1999) Comparison of cefuroxime axetil and phenoxymethyl penicillin for the treatment of children with solitary erythema migrans. Wien Klin Wochenschr 111: 916-922.

14. Gold B, Rodriguez WJ (1983) Cefuroxime: mechanisms of action, antimicrobial activity, pharmacokinetics, clinical applications, adverse reactions and therapeutic indications. Pharmacotherapy 3: 82-100

15. Gurevich E, Tchernin D, Schreyber R, Muller R, Leibovitz E (2016) Follow-up after infants younger than 2 months of age with urinary tract infection in southern israel: epidemiologic, microbiologic and disease recurrence characteristics. Braz J Infect Dis 20: 19-25. [Crossref]

16. Bitsori M, Maraki S, Galanakis E (2014) Long-term Resistance Trends of Uropathogens and Association With Antimicrobial Prophylaxis. Pediatr Nephrol 29: 1053-1058.

17. Bi X-C, Zhang B, Ye Y-K, He H-C, Han Z-D, et al. (2009) Pathogen incidence and antibiotic resistance patterns of catheter-associated urinary tract infection in children. $J$ Chemother 21: 661-665. [Crossref]

18. Knoderer CA, Cox EG, Berg MD, Webster AH, Turrentine MW (2011) Efficacy of limited cefuroxime prophylaxis in pediatric patients after cardiovascular surgery. Am J Health Syst Pharm 68: 909-914.

19. Brogden RN, Heel RC, Speight TM, G S Avery (1979) Cefuroxime: a review of its antibacterial activity, pharmacological properties and therapeutic use. Drugs 17: 233236

20. Nelson J, Kusmiesz H, Shelton S (1982) Cefuroxime therapy for pneumonia in infants and children. Pediatr Infect Dis 1: 159-163. [Crossref]

21. Pichichero ME (2000) Acute otitis media: part ii. treatment in an era of increasing antibiotic resistance. Am Fam Physician 61: 2410-2416.

22. Shafina MNN, Azizah AN, Mohammad AR, Faisal MF, Ikhsan SM, et al. (2015) Bacterial pathogens and antibiotic resistance patterns in children with urinary tract infection in a malaysian tertiary hospital. Med J Malaysia 70: 153-157. [Crossref]

23. Wald ER (1992) Antimicrobial therapy of pediatric patients with sinusitis. J Allergy Clin Immunol 90: 469-473.

24. Kamal SS, Hyldig N, Krych L, Greisen G, Krogfelt KA, et al. (2019) Impact of early exposure to cefuroxime on the composition of the gut microbiota in infants following cesarean delivery. J Pediatric 210: 99-105. [Crossref]

25. Carlier M, Noë M, Roberts JA, Stove V, Verstraete AG, et al. (2014) Population pharmacokinetics and dosing simulations of cefuroxime in critically ill patients: nonstandard dosing approaches are required to achieve therapeutic exposures. $J$ Antimicrob Chemother 69: 2797-2803.

26. Ibar-Bariain M, Rodríguez-Gascón A, Isla A, Solinís AA, Canut-Blascocorresponding A (2019) Application of pharmacokinetic/pharmacodynamic analysis to evaluate the adequacy of antimicrobial therapy for pediatric acute otitis media in Spain before and after the introduction of the PCV7 vaccine. Rev Esp Quimioter 32: 121-129.

27. Pichichero ME, Doern GV, Kuti JL, Nicolau DP (2012) Probability of achieving requisite pharmacodynamic exposure for oral $\beta$-lactam regimens against haemophilus influenzae in children. Paediatric Drugs 10: 391-397. [Crossref] 
28. Wormser GP, Nadelman RB, Dattwyler RJ, Dennis DT, Shapiro E, et al. (2020) practice guidelines for the treatment of lyme disease. Clin Infect Dis 31(Supplement 1): 1-14.

29. Luger SW, Paparone P, Wormser GP, Nadelman RB, Grunwaldt E, et al. (1995) Comparison of cefuroxime axetil and doxycycline in treatment of patients with early lyme disease associated with erythema migrans. Antimicrob Agents Chemother 39: 661-667.

30. Gerber MA, Shapiro ED, Burke GS, Parcells VJ, Bell GL, et al. (1996) Lyme disease in children in southeastern connecticut. $N$ Engl J Med 335: 1270-1274.

31. Rochette A, Rancourt M-P, Sola C, Prodhomme O, Saguintaah, M et al (2016) Cerebrospinal fluid volume in neonates undergoing. Br J Anaest 117: 214-19.

32. Pfenninger J, Schaad UB, Lütschg J, Nussbaumer A, Zellweger U (1982) Cefuroxime in bacterial meningitis. Arch Dis Child 57: 539-543. [Crossref]

33. Edwards MS, Baker CJ, Butler KM, Mason EO Jr, Laurent JP et al. (1989) Penetration of cefuroxime into ventricular fluid in cerebrospinal. Antimicrob Agents Chemother 33: $1108-1110$.

34. Kuzemko JA, Walker SR (1979) Cefuroxime plasma and CSF levels in children with meningitis. Arch Dis Child 54: 235-236.

35. Sirinavin S, Chiemchanya S, Visudhipan P, Lolekha S (1984) Cefuroxime treatment of bacterial meningitis in infants and children. Antimicrob Agents Chemother 25: 273275. [Crossref]

36. Del Rio MDLA, Chrane DF, Shelton S, McCracken Jr GH, Nelson JD (1982) Pharmacokinetics of cefuroxime in infants and children with. Antimicrob Agents Chemother 22: 990-994.

37. Philipson A, Stiernstedt G (1982) Pharmacokinetics of cefuroxime in pregnancy. Am J Obstet Gynecol 88: 146-149.

38. Gertler R, Gruber M, Wiesner G, Grassin-Delyle S, Urien S, et al. (2018) Pharmacokinetics of cefuroxime in infants and neonates undergoing cardiac surgery. Br J Clin Pharmacol 84: 2020-2028.
39. Powell DA, James NC, Ossi MJ, Nahata MC, Donn KH (1991) Pharmacokinetics of cefuroxime axetil suspension in infants and children. Antimicrob Agents Chemother 35 : 2042-2045. [Crossref]

40. Knoderer CA, Saft SA, Walker SG, Rodefeld MD, Turrentine MW, et al. (2011) Cefuroxime pharmacokinetics in pediatric cardiovascular surgery patients undergoing cardiopulmonary bypass. J Cardiothorac Vasc Anesth 25: 425-430.

41. Källman O, Fendukly F, Karlsson I, Kronvall G (2003) Contribution of efflux to cefuroxime resistance in clinical isolates of escherichia coli. Scand J Infect Dis 35: $464-470$

42. Källman O, Motakefi A, Wretlind B, Kalin M, Olsson-Liljequist B, et al. (2008) Cefuroxime non-susceptibility in multidrug-resistant klebsiella pneumoniae overexpressing rama and acra and expressing ompk35 at reduced levels. J Antimicrob Chemother 62: 986-990.

43. Alam MZ, Aqil F, Ahmad I, Ahmad S (2014) Incidence and transferability of antibiotic resistance in the enteric bacteria isolated from hospital wastewater. Braz J Microbiol 44: 799-806.

44. Gunduz S, Altun HU (2018) Antibiotic Resistance patterns of urinary tract pathogens in turkish children. Glob Health Res Policy 3: 10.

45. Leibovici L, Berger R, Gruenewald T, Yahav J, Yehezkelli Y, et al. (2001) Departmental consumption of antibiotic drugs and subsequent resistance: A quantitative link. $J$ Antimicrob Chemother 48: 535-540.

46. Chen IL, Lee CH, Su LH, Tang YF, Chang SJ, et al. (2013) Antibiotic consumption and healthcare-associated infections caused by multidrug-resistant gram-negative bacilli at a large medical center in Taiwan from 2002 to 2009: implicating the importance of antibiotic stewardship. PLoS One 8: e65621.

47. Siesing PC, Alva-Jørgensen JP, Brodersen J, Arpi M, Jensen PE, et al. (2013) Rising incidence of enterococcus species in microbiological specimens from orthopedic patients correlates to increased use of cefuroxime: a study concentrating on tissue samples. Acta Orthop 84: 319-322.

48. Veličković-Radovanović R, Stefanović N, Damnjanović I, Kocić B, Antić S, et al. (2015) Monitoring of antibiotic consumption and development of resistance by enterobacteria in a tertiary care hospital. J Clin Pharm Ther 40: 426-430.

Copyright: @2020 Pacifici GM. This is an open-access article distributed under the terms of the Creative Commons Attribution License, which permits unrestricted use, distribution, and reproduction in any medium, provided the original author and source are credited. 